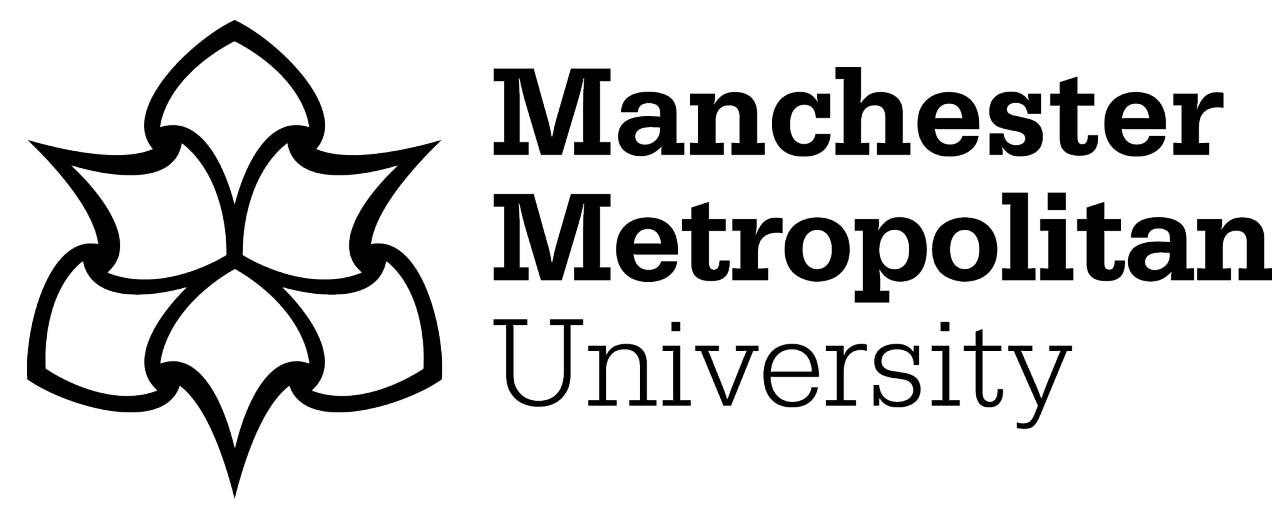

Davies, H and llott, S (2018) Gender, sexuality and the body in comedy: performance, reiteration, resistance. Comedy Studies, 9 (1). pp. 2-5. ISSN 2040-610X

Downloaded from: https://e-space.mmu.ac.uk/621042/

Version: Accepted Version

Publisher: Routledge

DOI: https://doi.org/10.1080/2040610X.2018.1437163

Please cite the published version 


\title{
Gender, Sexuality and the Body in Comedy: performance, reiteration, resistance
}

\author{
Helen Davies ${ }^{\text {a* }}$ and Sarah Ilott ${ }^{\mathrm{b}^{* *}}$ \\ ${ }^{a}$ Department of Humanities, Newman University, Birmingham, UK; ${ }^{b}$ Department of English, \\ Manchester Metropolitan University, Manchester, UK. \\ *H.C.Davies@newman.ac.uk \\ **S.Ilott@mmu.ac.uk
}

Helen Davies is Head of English and Creative Writing at Newman University, Birmingham. She is the author of Gender and Ventriloquism in Victorian and Neo-Victorian Fiction: Passionate Puppets (2012, Palgrave Macmillan) and Neo-Victorian Freakery: The Cultural Afterlife of the Victorian Freak Show (2015, Palgrave Macmillan). She has published widely in relation to neo-Victorianism and the politics of gender, sexuality, and disability, and is co-editor (with Sarah Ilott) of Comedy and the Politics of Representation: Mocking the Weak (forthcoming 2018, Palgrave Macmillan).

Sarah Ilott is a Lecturer in Literature and Film at Manchester Metropolitan University. She is the author of New Postcolonial British Genres: Shifting the Boundaries (2015, Palgrave Macmillan). Sarah has published widely in the fields of postcolonialism, the gothic, and comedy studies and is coeditor (with Helen Davies) of Comedy and the Politics of Representation: Mocking the Weak (forthcoming 2018, Palgrave Macmillan). 


\section{Gender, Sexuality and the Body in Comedy: performance, reiteration, resistance}

Comedy has an important political role in entrenching or overturning existing hierarchies of power, and these are identified through reading strategies that take seriously questions of representation. This was the logic behind the organisation of 'Mock the Weak: Comedy and the Politics of Representation', the conference that birthed the papers collected in this special edition. Co-organised by Dr Helen Davies and Dr Sarah Ilott (that's us!), the conference took place at Teesside University and Stockton Arc in September 2016. Collected here are some of the best papers on the topics of gender, sexuality, and the body originally produced for the conference.

The aims of the conference were threefold. As researchers working broadly in the field of English Studies, we wanted to centralise the contribution that this discipline can make to comedy studies, through its focus on cultural representation. By bringing the text-based reading practices of approaches such as feminism, postcolonialism and disability studies to the study of cultural texts in the comic mode, we aimed to broaden the study of comedy. Nevertheless, we recognised that the researchers in comedy were members of a diverse school, and as such we wanted to bring together academics from a range of disciplinary backgrounds in order to establish meaningful cross-disciplinary exchange. Finally, we sought to contextualise academic research into the representation of minority identities through reference to cultural industry workers and practitioners - both writers and performers - engaged daily in practical considerations of diversity and representation. 
The conference was designed to explore the various power dynamics at work to represent certain individuals as Other - to 'mock the weak' - as well as exploring strategies for resistance that have been actualised in comedies. We saw this as being a particularly important topic in the current climate, in which debates surrounding freedom of speech and the right to be protected from offence are frequently in evidence in relation to controversial jokes, sketches and comedies (think, for example, of the controversies surrounding the publication of The Satanic Verses, which centred on the comically bawdy representation of the Prophet, the release of The Interview, which parodied North Korean dictator Kim Jong-Un, or the Danish Cartoon and Charlie Hebdo affairs, both of which concerned the visual representation of the Prophet for entertainment). Building on the important work of Richard Dyer $(1993,1)$, who avowed that 'How we are seen determines in part how we are treated; how we treat others is based on how we see them; such seeing comes from representation', we sought to take seriously the representational strategies employed by comedy writers, producers and performers.

The first day of the conference gave early career academics the opportunity to attend workshops on writing comedy, with screen, radio and theatre writer Eddie Robson, and on publishing in the field with leading comedy academic Dr Rosie White. The conference proper opened the following day at Stockton Arc with a keynote by Professor Anshuman Mondal, an expert on postcolonial theory whose recent work focuses on the representation of Muslims, particularly in relation to freedom of speech controversies. His paper, 'Taking Liberties? Free speech, multiculturalism and the ethics of satire' provided an excellent start to proceedings, engaging with reading strategies and notions of offence in relation to a historically contextualised discussion of satire. Following a series of stimulating panels on representations of class, nationalism and religion, and questions of privilege, delegates were treated to a rendition of Not Safe For Work, performed by Teesside University's Performing Arts students 
under the direction of Dr Sarah O'Brien. The final day of proceedings was kicked off by Dr Sharon Lockyer, director of the Centre for Comedy Studies at Brunel, whose engaging paper on 'Reversing Disability Discourses in Live Comic Performance' was drawn from recent research exploring disability in stand-up comedy through interview and performance analysis. Following papers on representations of age, disability, and women, delegates were able to enjoy stand-up performances compered by BBC Trans Comedy Award's Claire Parker. The conference was rounded off with an industry roundtable that involved the keynote speakers alongside Akua Gyamfi (founder of The British Blacklist), Matthew Greenhough (writer and actor in Bismillah! An Isis Tragicomedy), Kate Smurthwaite (feminist comedian and political activist), Lynne Parker (founder of Funny Women) and Claire Parker (a comedian who is also a trans woman). The roundtable addressed questions raised elsewhere in the conference into the context of pressures uniquely experienced as industry workers and cultural producers, ensuring that there was a dialogue between academic researchers and those working actively in the field.

Our decision to dedicate a special issue to the theme of gender, sexuality and the body reflects our own commitment to feminist analysis and critique of comedy, but also recognises the critical investment in these issues which emerged at the conference. It seems a truism to suggest that matters of the 'body' are central to thinking about gender, sexuality and identity in culture, but 'bodies' are also of great significance to the aesthetics, theories, and politics of comedy as well. Magda Romanska and Alan Ackerman have noted that 'comedy often seems to privilege the life of the body over that of the mind (though the relative importance of body and mind in comedy is contested)' (Romanska and Ackerman 2017, 3); their key, cautionary term here is 'seems to', for their work demonstrates that the binary of 'mind/body' is just as problematic and permeable as the related division of 'gender/sex'. Judith Butler's theorisation 
of performative gender demonstrates that the 'body' - supposedly 'natural' or 'neutral' - is never beyond the discursive laws which construct 'gender' as well (Butler 1999, 10-11). Indeed, as this collection of articles demonstrates, the comedic representation of bodies are always shaped by normative ideologies of class, race, and disability, as well as gender and sexuality.

The special edition begins with Ellie Tomsett's article, 'Positives and Negatives: Reclaiming the female body and self-deprecation in stand-up comedy'. Her work explores the various sites of marginalisation and/or exploitation that women might experience in society, and considers how self-deprecation can be used by women in comedy as a strategy of resistance against such pressures. Via analysis of case studies of female stand-up performers such as Sarah Millican, Kiri Pritchard McLean, Dotty Winters, and Luisa Omielan, she demonstrates the ambivalence of self-deprecation as a feminist strategy of resistance; it can offer liberation from stereotypes of femininity, but also reinforce these restrictive attitudes at the same time.

Kate Fox's 'How Stand-Ups Construct and are Constructed by the "Northerness Effect"' also engages with the forum of stand-up, and considers the ways in which the 'North' is constructed as the working-class, feminised 'Other' in relation to the privileged centre of culture and taste of the socially and economically powerful South of Britain. Her analysis of interviews with stand-up comedians and of media coverage of their performance highlights particular anxieties around accent and voice as markers of gendered and economic inferiority and marginalisation. However, her analysis also suggests that stand-up is a form in which the Northern imaginary and hegemonic working-class masculinities and femininities can be challenged and resisted, as well as potentially reinforced, illustrating how contemporary 
Northern stand-ups Sophie Willan, Janice Connolly and Lucy Beaumont have enacted this resistance by 'Queering' ways of being a Northern woman.

Neil Washbourne’s ‘Adam Sandler as (questionable) masculine "role model”: Towards an analysis of disgust and violence in Adam Sandler's comedian comedy' positions Sandler's films as rich seams of enquiry into contemporary gender and sexual politics, but is cautious about the extent to which dominant forms of masculinity are really being challenged by Sandler's work. Deploying the concept of 'comedian comedy', Washbourne's article explores the ways in which the films invoke stereotypes of disgust, violence and fear towards women and gay men without posing a serious challenge to the status quo.

Dejan Jontes' and Andreja Trdina's 'Ridiculing the working class body in PostSocialist Sitcom' analyses representations of class, body, gender and nationality in the three most popular sitcoms of the last two decades in Slovenia, focusing especially on their role in working-class discourse and its transformation. Ambivalent representations of working-class characters are highlighted and put in the context of the egalitarian ideology which prevails in Slovenian popular culture. Drawing on the difference between workplace and domestic sitcoms, Jontes and Trdina concludes that the appearance and performance of working-class characters may be interpreted as a reworking of class boundaries in the post-socialist context. Sitcoms are thus considered as contributing to a process of re-demarcating class boundaries, yet with a subtle mockery at the level of their bodies rather than by explicit vilification of the lower classes in general.

Beccy Collins's 'British Dark Comedy television and the bodily aesthetics of the "proper person"' considers how 'dark comedy' represents the vulnerability of bodies to 
injury, ridicule, sickness and disease, with characters often being represented as having disabilities. She notes the potential for dark comedy to expose prejudice itself to ridicule, and yet demonstrates that frequently series such as Little Britain, Psychoville, and Tramadol Nights represents characters with disabilities as not fully human. The article explores this in relation to the idea that dark comedy programmes and their distinctive bodily aesthetics can provide an opportunity for viewers first to engage with, then dismiss, fears surrounding physical fragility and mortality.

Though this special edition is focused on representational strategies relating to gender, sexuality, and the body, those with interests in the wider concerns of the conference are invited to look out for our forthcoming edited collection, Comedy and the Politics of Representation: Mocking the Weak (Palgrave, 2018). This collection brings together papers that were also drawn from the conference on topics as diverse as religion, race and racism, class, nationalism, representations of Hitler, the ethics of satire and questions of authenticity and trust in relation to stand-up performance.

\section{References}

Butler, Judith. 1999. Gender Trouble: Feminism and the Subversion of Identity. London and New York: Routledge.

Dyer, Richard. 1993. The Matter of Images: Essays on Representation. London: Routledge. 
Romanska, Magda, and Ackerman, Alan. 2017. Reader in Comedy: An Anthology of Theory and Criticism. London: Bloomsbury. 